1 Universidade Federal do Rio de Janeiro (UFRJ), Escola de Servicco Social, Programa de Pós-Graduação em Serviço Social - Rio de Janeiro (RJ) Brasil.

ludmila.ufrj@gmail.com

2 Universidade de Fortaleza (Unifor), Programa de Pós-Graduação em Saúde Coletiva - Fortaleza (CE), Brasil.

gracyremigio@gmail.com

3 Universidade de Fortaleza (Unifor), Programa de Pós-Graduação em Saúde Coletiva - Fortaleza (CE),

Brasil.

janeeyre@unifor.br

4 Universidade de Fortaleza (Unifor), Programa de Pós-Graduação em Saúde Coletiva - Fortaleza (CE), Brasil.

rmsilva@unifor.br

\section{Implementação da atenção em saúde às violências sexuais contra as mulheres em duas capitais brasileiras}

\author{
Implementation of health care to sexual violence against women in \\ two Brazilian capitals
}

Ludmila Fontenele Cavalcanti, Gracyelle Alves Remigio Moreira², Luiza Jane Eyre de Souza

Vieira ${ }^{3}$, Raimunda Magalhães da Silva4

RESUMO Este artigo analisa a implementação da atenção em saúde às mulheres em situação de violência sexual em duas capitais brasileiras (Rio de Janeiro/Fortaleza). O estudo qualitativo analisou documentos sobre o tema e entrevistas semiestruturadas com 37 gestores dos sistemas de saúde municipais. A questão vem sendo abordada de forma diferenciada pelos municípios, o que decorre das distintas trajetórias de consolidação dos serviços, das aproximações com o movimento feminista e dos contextos culturais específicos. Notou-se que a implementação das ações nesse âmbito ainda apresenta fragilidades, exigindo esforços de articulação política e técnica para a estruturação e a manutenção dos serviços.

PALAVRAS-CHAVE Políticas públicas de saúde; Violência sexual; Violência contra a mulher; Atenção à saúde.

ABSTRACT This article analyzes the implementation of health care to women in situations of sexual violence in two Brazilian capitals (Rio de Janeiro/Fortaleza). The qualitative study analyzed documents about the subject and semi-structured interviews with 37 managers of the municipal health care system. The issue has been addressed in different forms by the municipalities, which arises from the different paths of the consolidation of services, the approaches to the feminist movement and to the specific cultural contexts. It was noted that the implementation of actions in this area still has weaknesses, demanding efforts of political and technique articulations for the structuring and maintenance of services.

KEYWORDS Public health policy; Sexual violence; Violence against women; Health care (Public health). 


\section{Introdução}

A violência sexual contra a mulher, como uma das expressões da violência de gênero, é um problema complexo que reflete as assimetrias de poder que marcam as relações sociais entre os sexos. Constitui-se em um problema social que impacta de maneira significativa o modo de viver, adoecer e morrer das mulheres. Nessa perspectiva, o fenômeno é considerado, mundialmente, uma das principais formas de violação dos direitos humanos e um problema de saúde pública (GARCÍAMORENO ET AL., 2015).

Ao longo das últimas décadas, esse tema vem ganhando visibilidade, tornando-se alvo de discussões em diferentes campos disciplinares e por entidades internacionais, o que demandou a formulação de políticas e programas, assim como a organização de práticas e serviços voltados para o seu enfrentamento. O Brasil, comprometido com pactos firmados internacionalmente, passou a investir na formulação de uma agenda de políticas, envolvendo alterações dos marcos legais e construção de modelos de atenção nas diferentes áreas de atuação pública.

Reportando-se especificamente ao setor saúde, o Ministério da Saúde, reconhecendo que a violência sexual afeta substancialmente o processo saúde-doença das mulheres, vem desenvolvendo recomendações, diretrizes e ferramentas programáticas para melhorar a resposta à violência sexual. $\mathrm{O}$ processo de inclusão do fenômeno no rol das responsabilidades do setor saúde teve como marco a publicação, no ano de 1999, da norma técnica 'Prevenção e tratamento dos agravos resultantes da violência sexual contra mulheres e adolescentes' (BRASIL, 1999). O documento passou por revisões e atualizações (BRASIL, 2012) em virtude do conhecimento técnico acumulado e do surgimento de novas demandas; e configura-se o principal instrumento organizador dos serviços e direcionador das ações, lançando as bases operacionais da atenção em saúde às mulheres nessa situação.

Não obstante, apesar dos avanços trazidos por essas iniciativas e do protagonismo do movimento feminista no enfrentamento da questão, a implementação da atenção em saúde às mulheres em situação de violência sexual está longe de cumprir o que está idealizado, exigindo continuados esforços de articulação política e técnica para a estruturação e a manutenção dos serviços.

Este trabalho emergiu da necessidade de se analisar o processo de implementação dessa atenção na rede municipal de saúde do Rio de Janeiro (RJ) e de Fortaleza (CE). A escolha da instância municipal justifica-se tanto pelo maior número de serviços voltados para a atenção a essa demanda quanto pelo protagonismo na articulação da rede de serviços locais. A seleção desses dois municípios pautou-se no fato de representarem contextos culturais distintos, pertencentes a polos diferenciados no que se refere aos indicadores sociais e de violência. Essa heterogeneidade entre os locais de estudo permite o conhecimento e o acompanhamento das ações governamentais em cenários distintos, com vistas a realimentar decisões e consolidar as estratégias.

Este estudo, baseado na análise de implementação de políticas públicas (DRAIBE, 2001), pretende contribuir com a identificação dos aspectos exitosos e os principais limites e desafios no desenvolvimento da atenção em saúde às mulheres em situação de violência sexual, apontando pontos cruciais para a correção de rumos. Nesse sentido, objetivou-se analisar a implementação da atenção em saúde a essa demanda em duas capitais brasileiras.

\section{Método}

Este trabalho é parte de uma pesquisa mais ampla, interinstitucional, que teve como objetivo analisar os serviços de saúde na 
atenção às mulheres em situação de violência sexual nos municípios do Rio de Janeiro e de Fortaleza. Trata-se de um estudo de abordagem qualitativa, visando à compreensão dos fatores facilitadores e dos obstáculos que operam, ao longo da implementação, e que condicionam, positiva ou negativamente, o cumprimento das metas e dos objetivos da intervenção (DRAIBE, 2001).

Utilizou-se a triangulação de fontes para a obtenção dos dados, apoiando-se em materiais e documentos institucionais disponíveis nas Secretarias Municipais de Saúde (SMS) e na internet, além de entrevistas realizadas com gestores dos sistemas de saúde municipais. Essa triangulação possibilitou uma análise mais consistente da implementação da atenção em saúde às mulheres em situação de violência sexual, uma vez que informações de fontes diferenciadas permitem a refutação de fatos ou apontam contradições.

Os materiais consultados foram publicados entre os anos de 2006 e 2013 e constituíram-se de matérias de jornais locais, documentos das secretarias municipais de saúde do Rio de Janeiro e de Fortaleza, documentos das secretarias estaduais de saúde do Rio de Janeiro e do Ceará, documentos de outros órgãos governamentais e de Organizações Não Governamentais (ONGs). Adotaram-se como critérios de inclusão dos materiais: matérias e documentos institucionais que abordassem ações municipais no enfrentamento à violência sexual contra a mulher; materiais publicados a partir de 2006, ano em que foi promulgada a Lei Maria da Penha (BRASIL, 2006). Essa lei, oriunda do movimento feminista, representou um avanço legislativo ao coibir e prevenir a violência contra a mulher; ao criar os Juizados de Violência Doméstica e Familiar contra as Mulheres, com competência cível e criminal; e ao estabelecer medidas de assistência e proteção às mulheres em situação de violência.

O acesso ao acervo ocorreu nos meses de janeiro a março de 2014, por meio dos endereços eletrônicos dos principais jornais circulantes no Rio de Janeiro e em Fortaleza, nos sites das secretarias municipais e estaduais das referidas localidades e nas páginas eletrônicas de ONGs que abordam o tema violência sexual contra a mulher.

Considerando que políticas e programas de saúde são implementados por pessoas, que os operacionalizam segundo seus valores, interesses e opções (DRAIBE, 2001), participaram da pesquisa 34 profissionais da gestão dos serviços da rede hospitalar dos municípios do Rio de Janeiro (19) e de Fortaleza (15), além de três gestores (dois no Rio de Janeiro e um de Fortaleza) do nível central das secretarias municipais de saúde, totalizando 37 entrevistados. A proposta foi se aproximar da realidade na perspectiva dos gestores, que são os agentes responsáveis, entre outras atividades, pelo planejamento e pela coordenação das ações.

Adotaram-se como critérios de inclusão dos participantes: ser gestor dos hospitais municipais de referência na atenção às mulheres em situação de violência sexual (diretor executivo, técnico e clínico; coordenação ou direção de setores institucionais envolvidos com a questão); e ser gestor do nível central indicado como responsável pelas ações relativas a essa atenção nos municípios.

Para a coleta de dados com os gestores, foram realizadas entrevistas semiestruturadas baseadas em roteiro, no período de agosto a dezembro de 2013, com consentimento dos informantes, de forma individual e em ambiente reservado. As gravações tiveram média de 29 minutos por entrevista, sendo, posteriormente, transcritas na íntegra, codificadas com as siglas GR (Gestor Rio de Janeiro) e GF (Gestor Fortaleza) e numeradas de 1 a 37, como forma de preservar o anonimato dos participantes.

O conjunto de dados foi analisado segundo a técnica de análise de conteúdo, na modalidade temática (MINAYO, 2013). A análise das entrevistas constou de uma fase de pré-análise, 
em que foi feita uma leitura compreensiva do material, buscando-se uma visão de conjunto e a apreensão de informações pertinentes ao objeto do estudo. Procedeu-se à identificação de ideias centrais (núcleos de sentido) que compõem a comunicação. E, por fim, buscou-se estabelecer uma compreensão do material empírico articulando-o às diretrizes preconizadas pelas políticas públicas voltadas para a atenção em saúde às mulheres em situação de violência sexual e à apreensão dos contextos locais.

A pesquisa foi aprovada pelo Comitê de Ética em Pesquisa da Secretaria Municipal de Saúde e Defesa Civil do Rio de Janeiro, com parecer $45 \mathrm{~A} / 2013$.

\section{Resultados e discussão}

\section{Contextualização do fenômeno nos cenários estudados}

O município do Rio de Janeiro apresenta taxa de homicídio de 3,9 por 100.000 mulheres, ocupando a $22^{\mathrm{a}}$ posição no País (WAISELFISZ, 2012). No ano de 2012, apresentou taxa de 36,5 por 100.000 habitantes (5.923 casos de crimes contra a liberdade sexual) (FÓRUM BRASILEIRO DE SEGURANÇA PÚBLICA, 2013). Com relação às notificações das violências sexuais contra as mulheres realizadas pelo setor saúde, o município registrou 2.014 notificações no período de 2009 a 2013. Esses registros revelam que essas violências atingiram, com mais frequência, mulheres entre 20 e 29 anos, brancas e com ensino fundamental incompleto. Predominaram os casos ocorridos no mês de setembro, na residência da mulher e na via pública, em que o agressor foi um desconhecido (BRASIL, 2015).

Fortaleza foi considerada a $7^{\mathrm{a}}$ capital mais violenta do mundo e $2^{\mathrm{a}}$ do Brasil, com taxa de homicídio de 72,81 por 100.000 habitantes (ORTEGA, 2014) e uma das capitais mais atingidas pelo turismo sexual. No tocante às violências de gênero perpetradas contra mulheres, a taxa de homicídio é de 5,6 por
100.000 mulheres, ocupando a $16^{\mathrm{a}}$ posição no País (WAISELFISZ, 2012). Os registros estaduais da segurança pública revelam taxa de 17,2 por 100.000 habitantes (1.483 casos), referente aos crimes contra a liberdade sexual, em 2012 (FÓRUM BRASILEIRO DE SEGURANÇA PÚBLICA, 2013). O setor saúde empreendeu 148 notificações de violências sexuais contra as mulheres entre os anos de 2009 e 2013. Essas violências foram perpetradas, em sua maior parte, contra mulheres na faixa etária de 20 a 29 anos, pardas e com ensino fundamental incompleto; ocorreram com mais frequência no mês de janeiro, na residência da mulher e na via pública, sendo um desconhecido o principal agressor (BRASIL, 2015).

A respeito da diferença significativa das taxas de crimes contra a liberdade sexual e do número de notificações na área da saúde entre os cenários, considera-se que tais dados podem refletir, além de uma maior ocorrência de casos no Rio de Janeiro, o investimento desse município no aprimoramento dos sistemas de informação, o que resulta na visibilidade do fenômeno.

\section{Caracterização dos gestores}

No Rio de Janeiro, a maioria dos gestores era do sexo feminino, enquanto em Fortaleza sobressaíram-se os do sexo masculino. Nos dois municípios, predominaram os gestores na faixa etária de 50 a 59 anos, que se declararam unidos (casamento formal ou união estável) e de religião católica.

A formação médica predominou entre os participantes das duas capitais. Apesar disso, observou-se, no Rio de Janeiro, uma representativa atuação de enfermeiros na gestão dos serviços de saúde; e, em Fortaleza, outras formações da área da saúde, como serviço social e farmácia, também estiveram envolvidas na gestão. Nos dois grupos, predominaram os gestores com mais de 25 anos de formados e que possuem pós-graduação, com prevalência dos cursos de especialização em nível lato sensu. 


\section{Gestão da atenção em saúde às mulheres em situação de violência sexual}

O processo de implementação das ações de atenção em saúde às mulheres em situação de violência sexual apresenta diferenças significativas entre os locais. No município do Rio de Janeiro, esse processo foi iniciado na década de 90; as unidades de referência são, em sua maioria, maternidades; a gestão das ações voltadas à saúde da mulher situa-se em duas subsecretarias da Secretaria Municipal de Saúde (SMS) (Atenção Hospitalar, Urgência e Emergência; Promoção, Atenção Primária e Vigilância em Saúde); e o município dispõe de Secretaria Especial de Políticas para Mulheres (SPM-Rio), criada em 2013.

Fortaleza iniciou esse processo há cerca de 10 anos. As unidades de referência são, em grande parte, instituições hospitalares secundárias, e a gestão da atenção às situações de violência sexual encontra-se na área de saúde da mulher, que se localiza na Coordenadoria de Políticas e Organização das Redes de Atenção à Saúde, dentro da Célula de Atenção às Condições Crônicas. O município conta com uma Coordenadoria Especial de Políticas para as Mulheres, criada em 2007, na estrutura da Secretaria Municipal de Cidadania e Direitos Humanos.

Conforme mencionado anteriormente, a atenção em saúde às violências contra as mulheres vem sendo abordada de forma diferenciada pelos municípios estudados. No Rio de Janeiro, a localização da gestão dessa atenção na estrutura da SMS expressa a relevância atribuída às ações nesse âmbito, trabalhadas de modo transversal, com capilaridade para unidades de saúde de diferentes níveis de atenção. Isso é resultado da trajetória de consolidação das políticas públicas municipais nessa área. Em Fortaleza, verifica-se, ainda, relativa invisibilidade da atenção em saúde às violências na estrutura da SMS, decorrente do estágio em que se encontra o reconhecimento do problema no ciclo da política (HOWLETT; RAMESH; PERL, 2013), tendo em vista a recente incorporação do tema na agenda governamental.

Nesses contextos, a participação do movimento feminista, como ator político estratégico impulsionador da formulação de uma agenda, vem alcançando impactos distintos na gestão municipal. A interlocução com o movimento feminista no município de Fortaleza no enfrentamento às violências de gênero vem ocorrendo por intermédio do Observatório da Violência, da participação em organizações não governamentais e do fomento à criação de equipamentos de proteção às mulheres. No Rio de Janeiro, observa-se uma vinculação mais orgânica de gestoras da área da saúde ao movimento feminista, viabilizando sua participação no processo de capacitação de gestores e profissionais, na implementação de serviços e na definição das ações institucionais.

No Rio de Janeiro, o organismo responsável pelas políticas com recorte de gênero possui o status de secretaria, ainda que recentemente criada, o que possibilita maior capacidade de vocalizar as demandas de saúde da população feminina. Em Fortaleza, tal demanda é tratada por intermédio de coordenadoria na estrutura municipal, o que reduz as possibilidades de interferência nas respostas municipais sobre essa questão.

Os organismos de políticas para as mulheres trabalham na perspectiva da transversalidade de gênero na gestão das políticas públicas, buscando articulação intersetorial das ações municipais (BRASIL, 2007). Nesse sentido, o enfrentamento das violências de gênero contra as mulheres é considerado uma área prioritária de atuação de tais organismos, na direção da prevenção, assistência e garantia de direitos. García-Moreno et al. (2015) advogam que o envolvimento de organizações de 
mulheres e da comunidade pode aumentar a conscientização sobre a violência e os serviços disponíveis, além de promover atitudes mais respeitosas e equitativas com relação às mulheres e contra a violência. As autoras destacam que a existência de organizações de mulheres constitui-se num recurso valioso para os sistemas de saúde.

A partir da análise do material coletado na internet, verifica-se um crescimento da disseminação de notícias sobre violência de gênero contra a mulher, que alcança o maior número de matérias veiculadas no ano de 2013, nos dois municípios. O enfrentamento da violência sexual aparece com mais ênfase nos materiais oriundos do Rio de Janeiro, com destaque para as campanhas realizadas, os dados estatísticos e os programas de enfrentamento. Em Fortaleza, nota-se uma ênfase na operacionalização dos equipamentos criados, na realização de capacitações direcionadas aos profissionais da rede de atenção e no incremento às campanhas.

Esses dados confirmam a disparidade entre os dois municípios nesse processo. Enquanto o Rio de Janeiro, nos últimos anos, tem investido na divulgação da magnitude do fenômeno e nos modos de enfrentamento, Fortaleza vem empreendendo esforços na divulgação dos serviços especializados da rede e na qualificação dos recursos humanos atuantes nessa área. Ambos os municípios têm visibilizado o fenômeno por meio do desenvolvimento de campanhas alusivas a datas específicas. Nos dois municípios, a área da mulher tem sido a responsável por divulgar as ações através da mídia, no entanto, chama a atenção que, no Rio de Janeiro, o setor saúde também partilha dessas informações.

Além da construção de uma agenda pública na implementação da atenção em saúde às mulheres em situação de violência sexual, os municípios têm procurado apoiar-se na divulgação e na circulação de informações qualificadas ao público em geral (DRAIBE, 2001).

\section{Caracterização da atenção em saúde às mulheres em situaç̃o de violência sexual: um olhar sobre os municípios do Rio de Janeiro e de Fortaleza}

\section{ACESSO DAS MULHERES AOS SERVIC̣OS}

No Rio de Janeiro, o acesso das mulheres em situação de violência sexual à unidade de saúde ocorre por encaminhamento das delegacias distritais e especializadas (Delegacia Especializada de Atendimento à Mulher - Deam) ou por outras unidades de saúde. "Vêm por meio das delegacias, das Deam [...]" (GR4). "Muitas vezes elas vão para o Hospital Salgado Filho, e o hospital manda vir para cá" (GR7).

Em Fortaleza, o acesso ocorre por demanda espontânea. As mulheres que procuram os serviços espontaneamente o fazem como primeiro contato após a violência, principalmente através dos serviços de emergência.

Nós temos uma emergência tanto em clínica médica como em obstetrícia, então, a chegada é espontânea" (GF20). "Normalmente, elas chegam espontaneamente na emergência. (GF22).

O acesso das mulheres aos serviços de saúde por meio de encaminhamentos pela rede intra e intersetorial, no Rio de Janeiro, demonstra o funcionamento dessa rede de atendimento, com uma boa integração entre alguns setores envolvidos com a questão. Fato ainda incipiente em Fortaleza, que reflete uma desarticulação entre os serviços integrantes da rede.

Por outro lado, o acesso espontâneo pode representar o reconhecimento da necessidade da atenção em saúde pelas mulheres que sofreram uma violência sexual, assim como pode indicar a busca do serviço de saúde somente em ocasiões em que o ato provocou 'marcas'. Estudos confirmam essa assertiva, apontando que, na maioria das vezes, o primeiro contato das mulheres em situação de violência com o setor saúde ocorre a partir dos serviços de emergência, em virtude de lesões e agravos físicos (PEDROSA; SPINK, 2011; GARCÍA-MORENO ET AL., 2015). 


\section{PROCEDIMENTOS INSTITUCIONALIZADOS}

No Rio de Janeiro, é reconhecida por muitos entrevistados a adoção de protocolo, tomando como referência a norma técnica do Ministério da Saúde (BRASIL, 2012), além de protocolos elaborados pela própria unidade de saúde. "Protocolo é a norma técnica do Ministério da Saúde" (GR2). "Nós temos um protocolo que foi implantado praticamente quando eu assumi a direção, que é um Protocolo Operacional Padrão (POP), que orienta a conduta no caso de violência sexual." (GR16).

Em Fortaleza, os participantes informam a ausência de protocolo ou apresentam a compreensão de protocolo como sendo a notificação ou outro tipo de registro. Apenas um pequeno grupo de entrevistados informa a existência de protocolo escrito, referindo-se ao 'Protocolo do atendimento às mulheres e adolescentes vítimas e em situação de violência doméstica e sexual do hospital da mulher de fortaleza' (ForTALEZA, 2012), o qual não encontra-se totalmente implementado. "Não ocorre. A gente até tem conhecimento do protocolo... Não ocorre porque o hospital não tem esse serviço montado" (GF21). "A gente não tem protocolo, a gente tem uma folha de notificação que é específica para esses casos, e através dessa notificação que a gente remete à secretaria de saúde [...]" (GF28).

Os protocolos são, em grande parte dos serviços, adaptações da norma técnica (BRASIL, 2012) à realidade municipal. A elaboração de um protocolo, muitas vezes, reflete o investimento dos gestores locais na construção de uma política municipal, no planejamento e no monitoramento das ações; assim como favorece a identificação dos limites da área da saúde na abordagem da violência sexual contra as mulheres.

Adotar um protocolo permite que os profissionais tenham subsídios para realizar um atendimento mais preciso e eficiente diante dos casos de violência (HASSE; VIEIRA, 2014). Os protocolos, nesse âmbito, devem citar os serviços de referência, o fluxo de atendimento, os medicamentos necessários, as orientações e as informações que devem ser fornecidas, entre outros aspectos. Nessa perspectiva, a adoção de protocolos imprime qualidade às ações de cuidado e de gestão, viabilizando uma atenção que responda apropriadamente às mulheres em situação de violência sexual.

A inexistência de protocolo ou sua insuficiente aplicação em Fortaleza explica-se, por um lado, pela recente trajetória de implementação dessa atenção no conjunto de unidades da rede pública de saúde, e, por outro, pela falta de qualificação dos gestores na abordagem do fenômeno. Andalaft Neto et al. (2012) retratam, em estudo envolvendo 1.395 estabelecimentos de saúde que referiram atender mulheres e crianças que sofrem violência sexual no Brasil, a escassa utilização de protocolos pelos serviços: apenas $8 \%$ do total. Cabe ressaltar que a não utilização de protocolos que padronizem e normatizem essa atenção pode trazer dificuldades na condução dos casos, uma vez que os profissionais tendem a desconhecer o fluxo de atendimento, as ações previstas e os encaminhamentos necessários (PEDROSA; SPINK, 2011; HASSE; VIEIRA, 2014).

Sobre a realização das profilaxias das Doenças Sexualmente Transmissíveis (DST) e os respectivos aconselhamentos, o Rio de Janeiro realiza esses procedimentos sistematicamente, dispondo de kit com os medicamentos, fornecidos por médicos e enfermeiros. $\mathrm{O}$ aconselhamento refere-se aos efeitos da medicação, riscos envolvidos e acompanhamento multiprofissional.

São feitas na sala de admissão mesmo. Tem um kit de VVS que é levado para a sala [...] E aplicam as medicações e explicam porque ela está fazendo todas aquelas medicações e a importância delas. (GR6). 
"Tem um kit pronto na supervisão, e, depois do atendimento, o médico solicita à enfermeira que traga o kit [...] E a gente faz a entrega" (GR9).

Em Fortaleza, esses procedimentos ainda não estão instituídos em quase todas as unidades, sendo realizados em apenas um serviço de saúde municipal considerado de referência. Alguns gestores também mencionaram o encaminhamento das mulheres para unidades da gestão estadual para realização das profilaxias. "Desconheço que sejam feitas as profilaxias” (GF27).

Não, a gente só faz aqui o teste rápido do HIV para as pacientes que vão parir, porque é protocolo estabelecido. Mas, para vítima de violência, a gente não tem nada implantado. (GF20).

"Encaminha para outro hospital que seja estruturado. Normalmente, a orientação dos profissionais é que se encaminhe" (GF21).

As profilaxias das DST são medidas fundamentais para proteger a saúde sexual e reprodutiva das mulheres dos possíveis e intensos impactos do ato de violência a que foram submetidas. Dessa forma, os serviços de saúde necessitam estar organizados para atender a essa demanda de forma rápida e resolutiva, tendo em vista que esse cuidado é sensível ao tempo (GARCÍA-MORENO ET AL., 2015).

Nesse contexto, também é imprescindível o aconselhamento da mulher, tendo em vista que ele permite minimizar o dano emocional, além de favorecer uma melhor adesão aos esquemas medicamentosos. Torna-se fundamental nesse processo o esclarecimento precoce dos possíveis efeitos colaterais relacionados ao tratamento, bem como as formas de minimizá-los durante a sua utilização.

O aconselhamento, como processo de escuta ativa, ainda permite estabelecer relação de confiança entre a mulher e o profissional de saúde, facilitando a superação da situação traumática (BRASIL, 2012).

\section{Atendimento diante da gravidez de- corrente da violência sexual}

A oferta de anticoncepção de emergência também faz parte da rotina de atendimento no Rio de Janeiro, por meio de kit com a medicação, envolvendo médicos e enfermeiros no fornecimento. "Na emergência mesmo são colhidas as informações. A mulher é examinada e nessa hora são dadas todas as medicações, incluindo a anticoncepção de emergência” (GR5). Em Fortaleza, da mesma forma como acontece como as profilaxias das DST, essa oferta ocorre em apenas uma unidade municipal. "Como não existe o serviço montado, não existe contracepção de emergência" (GF35). "Não tem. Geralmente, a gente encaminha para o Gonzaguinha" (GF34).

Mesmo considerando que o uso da anticoncepção de emergência não se aplica a todas as situações de violência sexual, a prevenção da gravidez não desejada deve se constituir em elemento prioritário na atenção em saúde a essa demanda. A não oferta ou a demora desse procedimento pode submeter as mulheres a uma gestação decorrente de violência sexual. A gravidez, nessa situação, destaca-se pela complexidade das reações psicológicas e sociais que determina, representando, para a maioria das mulheres, uma segunda forma de violência. Nesse sentido, os profissionais de saúde precisam estar capacitados e instrumentalizados para o diagnóstico precoce e a prevenção dos problemas decorrentes dessa violência, bem como a gestão deve assegurar os recursos (medicamentos, suprimentos e equipamentos) necessários para as condutas preconizadas pela normatização (BRASIL, 2012).

A partir dos relatos dos gestores, evidencia-se que em Fortaleza apenas uma unidade da rede municipal hospitalar oferece as ações previstas na norma técnica. No entanto, recentemente, a Lei $\mathrm{n}^{\circ} 12.845 / 2013$ ampliou a oferta desse tipo de atenção, prevendo a obrigatoriedade do atendimento 
integral a pessoas em situação de violência sexual nos hospitais do Sistema Único de Saúde (SUS) (BRASIL, 2013). Dessa forma, todos os serviços tornam-se responsáveis por essa demanda, não sendo mais restrita às instituições consideradas de referência.

Com relação aos encaminhamentos realizados no caso de gravidez decorrente da violência sexual, o Rio de Janeiro possui apenas uma unidade de saúde de referência para o aborto previsto em lei. Os participantes também referem encaminhamentos para realização de pré-natal e para adoção.

Se ela está gestante devido a um estupro, a gente faz o Sinan [Sistema de Informação de Agravos de Notificação], vê a data da última menstruação, vê a data da violência, quanto tempo tem essa gestação. Ela vai depois para o serviço social, para a saúde mental e para o médico obstetra. Aí, todo mundo de acordo e tendo até 20 semanas de gestação, ela é internada para realizar o aborto. (GR1).

"A gente não faz o aborto legal aqui, a referência é a Fernando Magalhães" (GR9). "A gente oferece o pré-natal e informa à paciente que existe o pré-natal, e ela pode entregar a criança para adoção se ela quiser”. (GR10).

Fortaleza também possui apenas uma unidade de saúde de referência para o aborto previsto em lei. No entanto, a maioria dos entrevistados desconhece os procedimentos e considera que as respectivas unidades de saúde não possuem perfil para realização desse tipo de atendimento. "No caso, ela vai ser referenciada para um serviço que já exista, que seja montado. Quem vai dar essa orientação é o próprio serviço de referência” (GF21).

A gente normalmente referencia para o Hospital de Messejana, porque eles lá já são capacitados no caso da gravidez. Se a paciente deseja interromper, eles lá já têm profissionais aptos para isso. Nós aqui não temos (GF22).

Sobre o monitoramento dos casos encaminhados para o aborto previsto em lei, ambos os municípios informam que é realizado pela equipe de saúde, sendo que no Rio de Janeiro essa atribuição fica a cargo do serviço social.

A capacitação dos profissionais, a qualidade da informação e a eficácia do atendimento diante da gravidez decorrente da violência sexual podem ser consideradas indicadores positivos da institucionalização de uma perspectiva de gênero na implementação dessas ações.

Por outro lado, o desconhecimento, a resistência em executar o procedimento na unidade de saúde e a fragilidade no monitoramento dos casos indicam o despreparo dos gestores, agravado pelo preconceito frente ao aborto previsto em lei e pela existência de apenas um serviço de referência em cada um dos municípios.

Quando a violência sexual resulta em gravidez, a mulher, bem como a adolescente e seus representantes legais devem ser esclarecidos sobre as alternativas legais quanto ao destino da gestação e sobre as possibilidades de atenção nos serviços de saúde. O aborto, nesses casos, é um direito e não uma obrigação. Em razão disso, da mesma forma, as mulheres devem receber orientações sobre $o$ direito de manter a gestação até o seu término, assegurando os cuidados pré-natais apropriados para a situação, e sobre a alternativa de entrega da criança após o parto para adoção. Nessa última hipótese, os serviços de saúde devem providenciar as medidas necessárias junto às autoridades que compõem a rede de atendimento para garantir o processo regular de adoção (BRASIL, 2012). A decisão final cabe à mulher, e os profissionais de saúde devem respeitar sua autonomia, atuando como agentes que assegurem que essa decisão seja tomada de forma livre, consciente, esclarecida e informada.

Contudo, a questão do aborto é muito polêmica, e seu cumprimento esbarra em dificuldades administrativas e em questões culturais que influenciam a atuação da equipe de saúde na prestação desse atendimento. Para Colas, Aquino e Matar (2007), questões religiosas, sexuais ou familiares, de ordem pessoal dos profissionais, podem 
desestimular ou até mesmo restringir o acesso das mulheres ao aborto legal e seguro.

Vale discorrer que a objeção de consciência e a recusa do profissional de realizar a interrupção da gravidez devem ser respeitadas. Em contrapartida, as instituições necessitam oferecer condições para tal prática disponibilizando outros profissionais. A negação dessa prática pode levar a mulher a buscar um aborto em condições inseguras, o que constitui-se em um problema ainda maior, com sérias repercussões à sua saúde.

\section{Trabalho em rede}

Os entrevistados dos dois municípios identificam como instituições da rede intrasetorial as unidades voltadas para a saúde da mulher, Unidades de Pronto Atendimento (UPA), hospitais gerais e Unidades de Atenção Primária à Saúde (Uaps). Porém, observa-se uma diferença importante relativa às relações estabelecidas entre essas instituições. No Rio de Janeiro, os vínculos entre os serviços são formais, através de guia de referência, regulação de vagas, documentação e contato telefônico. Foi informada a existência de linha de cuidado adotada pela SMS. "A gente encaminha por guia de referência e contrarreferência" (GR4). "O encaminhamento, geralmente, é com um contato prévio. A gente entra em contato direto com o gestor local" (GR6).

Em Fortaleza, apesar dos contatos telefônicos e do estabelecimento de referência, através do serviço social e da central de leitos, verificam-se vínculos informais. " $O$ serviço social encaminha para as unidades que têm realmente fluxo" (GF20). "Normalmente, é via central de regulação, mas, às vezes, quando a central de regulação não funciona, é por amizade mesmo" (GF21).

Sobre a rede intersetorial, os gestores do Rio de Janeiro mencionam instituições da segurança pública (delegacias e Instituto Médico Legal - IML), conselhos de direito, Conselho Tutelar, universidades públicas,
Centro de Referência Especializado de Assistência Social (Creas), abrigos, defensoria pública e informam a existência de fluxo pré-estabelecido. Fortaleza possui uma rede que inclui instituições da segurança pública (delegacias e Perícia Forense), promotoria, centro de referência, organização não governamental e casa abrigo, todavia, não foi informado fluxo pré-estabelecido.

Os dois municípios apresentam dificuldades em apontar as formas de gerenciamento das redes intra e intersetorial, apesar do investimento de articulação das redes em ambos os municípios pelos gestores da área da saúde e da área da mulher. Alguns entrevistados não souberam responder sobre essa questão, o que pode estar associado à falta de conhecimento sobre a rede de atendimento às mulheres em situação de violência sexual ou à própria desarticulação dessa rede nos municípios.

O conceito de enfrentamento adotado pela Política Nacional de Enfrentamento à Violência contra as Mulheres diz respeito à implementação de políticas amplas e articuladas, que procurem dar conta da complexidade do fenômeno em todas as suas expressões. $\mathrm{O}$ enfrentamento requer a ação conjunta dos diversos setores envolvidos com a questão (saúde, segurança pública, justiça, educação, assistência social, entre outros), por meio da constituição da rede de atendimento (BRASIL, 2011).

Na perspectiva de uma atenção integral, torna-se imperioso ultrapassar ações institucionais isoladas, uma vez que a mera existência de vários serviços, trabalhando de formas distintas entre si, não é capaz de responder ao fenômeno. Nessa direção, Schraiber et al. (2012) reforçam que a configuração de uma 'rede' para um conjunto de serviços só é possível quando existe articulação entre as ações particulares de cada serviço, sendo concreta quando houver uma produção assistencial minimamente partilhada pelos diferentes setores que prestam assistência às mulheres em situação de violência. 
Verifica-se, nas realidades estudadas, a presença de algumas conexões já estabelecidas, tais como entre as Deam e as unidades hospitalares no Rio de Janeiro, ou entre os serviços que compõem a rede intrasetorial. Contudo, observa-se pouca integração e comunicação entre os setores no cenário de Fortaleza, fato ratificado pela inexistência de fluxo pré-estabelecido, prevalecendo a fragmentação das ações e o desconhecimento mútuo.

Segundo a norma técnica (BRASIL, 2012), o limite de atuação de cada unidade depende da disponibilidade de recursos; e situações de maior complexidade podem requerer mecanismos de referência e contrarreferência. Dessa forma, a construção e a consolidação da rede de serviços para o enfrentamento da violência contra as mulheres se configuram em umas das estratégias mais relevantes e desafiadoras para lidar com esse problema multifacetado, na medida em que fortalece as mulheres e também os profissionais, ao se sentirem amparados e encorajados a agir (HASSE; VIEIRA, 2014).

\section{Conclusões}

Apesar dos esforços de ambos os municípios em visibilizar o fenômeno da violência de gênero, as fragilidades relativas à qualificação da gestão na atenção às mulheres em situação de violência sexual apontam para a necessidade de inclusão desse tema na formação profissional.

Notadamente, há uma insuficiência de serviços de referência para o aborto previsto em lei nos dois cenários. Nesse sentido, pode ser considerada relevante a inclusão desse tema na agenda municipal, na perspectiva da garantia de direitos, a despeito das descontinuidades na implementação da atenção em saúde decorrentes das mudanças na gestão.

As gestões de ambos os municípios ainda estão iniciando o processo de produção da informação sobre esse agravo, indispensável ao monitoramento das ações de atenção às mulheres em situação de violência sexual na área da saúde. Isso pode estar associado ao distanciamento da gestão das ações de saúde das ações de enfrentamento à violência contra a mulher.

Assim como o fenômeno da violência sexual possui contornos específicos em cada um dos municípios, o processo de implementação das ações de atenção em saúde às mulheres em situação de violência sexual também apresenta diferenças significativas, o que pode estar relacionado ao estágio em que se encontra o reconhecimento do problema no ciclo político.

Apesar dos pontos de convergência, os resultados apontam para uma incorporação diferenciada dos dois municípios com relação aos parâmetros sugeridos pela norma técnica, decorrente da trajetória de consolidação dos serviços, da apropriação da categoria gênero por gestores e profissionais, da aproximação com o movimento feminista e dos contextos culturais específicos.

Nesse sentido, o processo de implementação em Fortaleza, comparado ao do Rio de Janeiro, mostra-se mais incipiente. Os procedimentos previstos na norma técnica (BRASIL, 2012), como: adoção de protocolo, realização das profilaxias das DST e os respectivos aconselhamentos, oferta de anticoncepção de emergência e encaminhamentos realizados no caso de gravidez decorrente da violência sexual não fazem parte da rotina dos serviços de saúde e, em sua maioria, são referenciados a uma única unidade de saúde.

Na direção de uma resposta mais efetiva na atenção em saúde às mulheres em situação de violência sexual, colocam-se como desafios para o município do Rio de Janeiro: ampliação do acesso aos serviços e ao direito ao aborto legal; fortalecimento do fluxo de atendimento com envolvimento das unidades nas pactuações da rede intra e intersetorial; e construção de um sistema de monitoramento voltado para o acompanhamento das usuárias após o atendimento emergencial, com a participação do nível primário de saúde.

Em Fortaleza, com vistas à institucionalização de uma perspectiva de gênero, é necessário 
esforço para promover a integração dos serviços da rede de atendimento. Sugerem-se: investimento na produção de materiais educativos dirigidos à instrumentalização dos profissionais; incorporação dos protocolos já estabelecidos; aumento da oferta das profilaxias das DST e da anticoncepção de emergência; ampliação do diálogo com as outras áreas de políticas públicas; e divulgação acerca dos dispositivos legais e da rede de serviços.

Torna-se relevante aos dois municípios o investimento permanente na articulação

\section{Referências}

ANDALAFT NETO, J. et al. Perfil do atendimento à violência sexual no Brasil. FEMINA, Rio de Janeiro, v. 40, n. 6, p. 301-306, 2012.

BRASIL. Ministério da Saúde. Sistema de informação de agravos de notificação (SINAN). Disponível em: $<$ http://dtr2004.saude.gov.br/sinanweb/>. Acesso em: 5 maio 2015

Ministério da Saúde. Secretaria de Atenção à Saúde. Departamento de Ações Programáticas Estratégicas. Prevenção e tratamento dos agravos resultantes da violência sexual contra mulheres e adolescentes: norma técnica. 3. ed. Brasília, DF: Ministério da Saúde, 2012.

Ministério da Saúde. Secretaria de Políticas de Saúde. Departamento de Gestão de Políticas Estratégicas. Prevenção e tratamento dos agravos resultantes da violência sexual contra mulheres e adolescentes: normas técnicas. Brasília, DF: Ministério da Saúde, 1999.

Presidência da República. Lei n. 11.340, de 7

de agosto de 2006. Cria mecanismos para coibir a violência doméstica e familiar contra a mulher, nos termos do $₫ 8$ o do art. 226 da Constituição Federal, da Convenção sobre a Eliminação de Todas as Formas de Discriminação contra as Mulheres e da Convenção Interamericana para Prevenir, Punir e Erradicar a Violência contra a Mulher; dispõe sobre a criação intersetorial para o enfrentamento à violência sexual contra as mulheres, tendo como protagonista a área da saúde. Essa articulação deve superar o mero encaminhamento de usuárias para a consolidação de um fluxo resolutivo, com a realização de ações integradas.

Resta salientar a importância desses resultados para pensar o desenho das políticas públicas municipais na consolidação da cidadania feminina, por meio de estratégias desenvolvidas em contextos e culturas institucionais distintas. dos Juizados de Violência Doméstica e Familiar contra a Mulher; altera o Código de Processo Penal, o Código Penal e a Lei de Execução Penal; e dá outras providências. Diário Oficial [da] União. Brasília, DF, 8 ago. 2006. Disponível em: <http://www.planalto.gov. br/ccivil_03/_ato2004-2006/2006/lei/111340.htm>. Acesso em: 10 nov. 2014.

Presidência da República. Secretaria Nacional de Enfrentamento à Violência contra as Mulheres. Secretaria de Políticas para as Mulheres. Política Nacional de Enfrentamento à Violência contra as Mulheres. Brasília, DF: Secretaria de Políticas para as Mulheres, 2011.

Presidência da República. Lei n. 12.845 , de $1^{\circ}$ de agosto de 2013. Dispõe sobre o atendimento obrigatório e integral de pessoas em situação de violência sexual. Diário Oficial [da] União. Brasília, DF, 1 ago. 2013. Disponível em: <http://www.planalto.gov.br/ ccivil_03/_ato2011-2014/2013/lei/112845.htm>. Acesso em: 10 nov. 2014.

Secretaria de Políticas para as Mulheres.

Enfrentamento à violência contra a mulher: balanço de ações 2006 - 2007. Brasília, DF: Secretaria de Políticas para as Mulheres, 2007.

COLAS, O.; AQUINO, N. M.; MATTAR, R. Ainda sobre o abortamento legal no Brasil e o conhecimento dos 
profissionais de saúde. Revista Brasileira de Ginecologia e Obstetrícia, Rio de Janeiro, v. 29, n. 9, p. 443-445, 2007.

DRAIBE, S. M. Avaliação de implementação: esboço de uma metodologia de trabalho em políticas públicas. In: BARREIRA, M. C. R. N.; CARVALHO, M. C. B. (Org.). Tendências e perspectivas na avaliação de políticas e programas sociais. São Paulo: IEE: PUC, 2001. p. 14-42.

FORTALEZA. Secretaria Municipal de Saúde de Fortaleza. Protocolo do atendimento às mulheres e adolescentes vítimas e em situação de violência doméstica e sexual. Fortaleza: Secretaria Municipal de Saúde de Fortaleza, 2012. Disponível em: < http://pt.scribd. com/doc/131289352/Hospital-Da-Mulher-LivroProcedimentos-Web\#scribd>. Acesso em: 15 jan. 2015.

\section{FÓRUM BRASILEIRO DE SEGURANÇA PÚBLICA.}

Anuário Brasileiro de Segurança Pública. São Paulo: Fórum Brasileiro de Segurança Pública, 2013. Disponível em: $<$ http://www.forumseguranca.org. br/storage/download//anuario_2013-corrigido.pdf>. Acesso em: 2 abr. 2015.

GARCÍA-MORENO, C. et al. The health-systems response to violence against women. The Lancet, Londres, v. 385, n. 9977, p. 1567-1579, 2015.

HASSE, M.; VIEIRA, E. M. Como os profissionais de saúde atendem mulheres em situação de violência? Uma análise triangulada de dados. Saúde em Debate, Rio de Janeiro, v. 38, n. 102, p. 482-493, 2014.
HOWLETT, M.; RAMESH, M.; PERL, A. (Org.).

Política pública: seus ciclos e subsistemas - uma abordagem integral. Rio de Janeiro: Elsevier, 2013.

MINAYO, M. C. S. O desafio do conhecimento: pesquisa qualitativa em saúde. 13. ed. São Paulo: Hucitec, 2013.

ORTEGA, J. A. Por tercer año consecutivo, San Pedro Sula es la ciudad más violenta del mundo. 2014.

Disponível em: <http://www.seguridadjusticiaypaz.org. $\mathrm{mx} /$ sala-de-prensa/941-por-tercer-ano-consecutivo-san-pedro-sula-es-la-ciudad-mas-violenta-del-mundo>. Acesso em: 17 nov. 2014.

PEDROSA, C. M.; SPINK, M. J. P. A violência contra mulher no cotidiano dos serviços de saúde: desafios para a formação médica. Saude Soc., São Paulo, v. 20, n. 1, p. 124-135, 2011.

SCHRAIBER, L. B. et al. Assistência a mulheres em situação de violência - da trama de serviços à rede intersetorial. Athenea, Cerdanyola del Vallès, v. 12, n. 3 , p. $237-254,2012$.

WAISELFISZ, J. J. Mapa da Violência 2012: atualização: homicídio de mulheres no Brasil. São Paulo: Cebela: Flacso Brasil, 2012.

\footnotetext{
Recebido para publicação em maio de 2015

Versão final em setembro de 2015

Conflito de interesses: inexistente

Suporte financeiro: Conselho Nacional de Desenvolvimento

Científico e Tecnológico (CNPq) através do Edital

MCTI/CNPq/SPM-PR/MDA № 32/2012 - Relações de Gênero,

Mulheres e Feminismos
} 